\title{
URBANIZAÇÃo ACELERAdA: RISCO PARA O ABASTECIMENTO DE ÁGUA NA REGIÃO METROPOLITANA DE GOIÂNIA
}

\author{
ACCELERATED URBANIZATION: RISK TO THE WATER SUPPLY IN GOIANIA METROPOLITAN REGION
}

\author{
Débora Ferreira da Cunha \\ Universidade Federal de Goiás (UFG), Goiânia, GO, Brasil, deboracunha.ufg@gmail.com \\ Elcileni de Melo Borges \\ Universidade Federal de Goiás (UFG), Goiânia, GO, Brasil, elcimb@uol.com.br
}

\begin{abstract}
RESUMO
As regiões metropolitanas apresentam problemas de abastecimento de água e tratamento de esgotos, principalmente os relacionados à proteção de mananciais, tratamento e distribuição de águas, pois, são áreas que concentram uma maior diversificação de usos múltiplos dos recursos hídricos. O crescimento da população urbana associado à expansão urbana, à degradação dos mananciais e à contaminação e poluição promovem aumento considerável nas demandas hídricas. Nesse contexto se insere a Região Metropolitana de Goiânia (RMG), que ao longo das últimas décadas, vem passando por um acelerado crescimento populacional e processo de urbanização, demonstrados pelos dados demográficos. Este trabalho propõe-se a discutir os impactos da expansão urbana da RMG na degradação dos mananciais hídricos, como causas do risco de escassez de água na região, evidenciadas pelo acentuado crescimento de assentamentos humanos e empreendimentos industriais nas áreas das bacias hidrográficas, comprometendo a quantidade e qualidade da água para o abastecimento. Entre as ameaças, riscos e limites para o sistema produtor de água da RMG, a estratégia para a gestão da água e enfrentamento do problema foi a construção do Sistema Produtor Mauro Borges, que engloba a barragem do Ribeirão João Leite e um complexo de instalações.
\end{abstract}

Palavras-chave: Urbanização. Expansão urbana. Abastecimento de água. Gestão da água. Região Metropolitana de Goiânia.

\begin{abstract}
Metropolitan regions present problems of water supply and sewage treatment, especially those related the protection of watersheds, water treatment and distribution, are areas that concentrate a greater diversification of multiple uses of water resources. Urban population growth associated with the urban sprawl, the degradation of watersheds and the contamination and pollution promote considerable increase in water demands. In this context is part of the Goiania metropolitan region (RMG), which over the past few decades, has been going through an accelerated population growth and urbanization process, demonstrated by demographics data. This work is proposing to debate the impacts of urban sprawl of RMG in the degradation of watersheds, as the risk of water shortage causes in the region, evidenced by the strong growth of human settlements and industrial enterprises in the areas of catchments areas, committing the water quantity and quality of supply. Amongst threats, risks and limits for the water producer system on RMG, the strategy for water management and confrontation of the problem was the construction of Mauro Borges producer system, included the dam the Ribeirão João Leite and a complex of facilities.
\end{abstract}

Keywords: Urbanization. Urban spraw. Water supply. Water management. Goiania Metropolitan Region.

Artigo recebido para publicação em fevereiro de 2015

Artigo aceito para publicação em maio de 2015

\section{INTRODUÇÃO}

O crescimento demográfico da Região Metropolitana de Goiânia (RMG) nas últimas décadas, associado à diversos fatores, entre eles, expansão econômica, aumento da fronteira agrícola do Estado, uso 
descontrolado de agrotóxicos, ocupação irregular do solo, tratamento não adequado do lixo e falta de conscientização do problema, são algumas das causas principais da degradação crescente dos recursos hídricos e das áreas a montante da captação de abastecimento público na região. Consequentemente, o risco de escassez de água na RMG soa como uma "tragédia anunciada", a qual vem sendo aventada há alguns anos por ambientalistas e pesquisadores; e a população local já sofre interrupções no serviço, principalmente no período da seca, sendo os municípios de Aparecida de Goiânia e Goiânia os mais afetados.

O sistema de abastecimento de água da RMG depende, quase que exclusivamente, do terço superior da bacia hidrográfica do Rio Meia Ponte e da metade inferior da sub-bacia do Ribeirão João Leite, região que passa por forte processo de degradação em vista do acelerado processo de urbanização no decorrer dos anos, ocasionando a contaminação das águas e alterações qualiquantitativas, inclusive pela existência de lixões/aterros sanitários dentro das microbacias dos mananciais. No início da década de 2000, a operação encontrava-se em sua capacidade máxima de vazão e o nível dos rios no limite mínimo necessário.

Nesses termos, este trabalho ${ }^{1}$ tem por objetivo discutir os impactos da expansão urbana da RMG na degradação dos mananciais hídricos, frente a recente estratégia de gestão para o abastecimento de água na região. A partir de levantamento bibliográfico, documental e informacional, busca-se caracterizar a estrutura do sistema de abastecimento de água da região e compreender os limites e as estratégias propostas para gestão do sistema. Considerando também os eminentes problemas socioambientais da região e seus territórios, decorrentes da urbanização. Assim, espera-se contribuir com os estudos e as discussões relativas às questões urbanas das regiões metropolitanas.

\section{Região Metropolitana de Goiânia: expansão e crescimento}

\footnotetext{
1 Trabalho apresentado no VI Congresso Iberoamericano de Estudios Territoriales y Ambientales, realizado em setembro/2014, São Paulo/USP, resultado de reflexões desenvolvidas no âmbito do Projeto Governança Metropolitana no Brasil (2012/2014), financiado pelo Instituto de Pesquisa Econômica Aplicada (Ipea).
} 
A $\mathrm{RMG}^{2}$ é um dos principais aglomerados urbanos do Brasil, localizada no estado de Goiás, composta por vinte municípios, possui uma área de $7.315,16 \mathrm{~km}^{2}$, com de 2,2 milhões de habitantes (IBGE, 2010), que representam 39,3\% da população urbana de Goiás. A Figura 1 mostra a expansão dos limites administrativos, evolução populacional e densidade demográfica dos municípios da RMG desde sua criação.

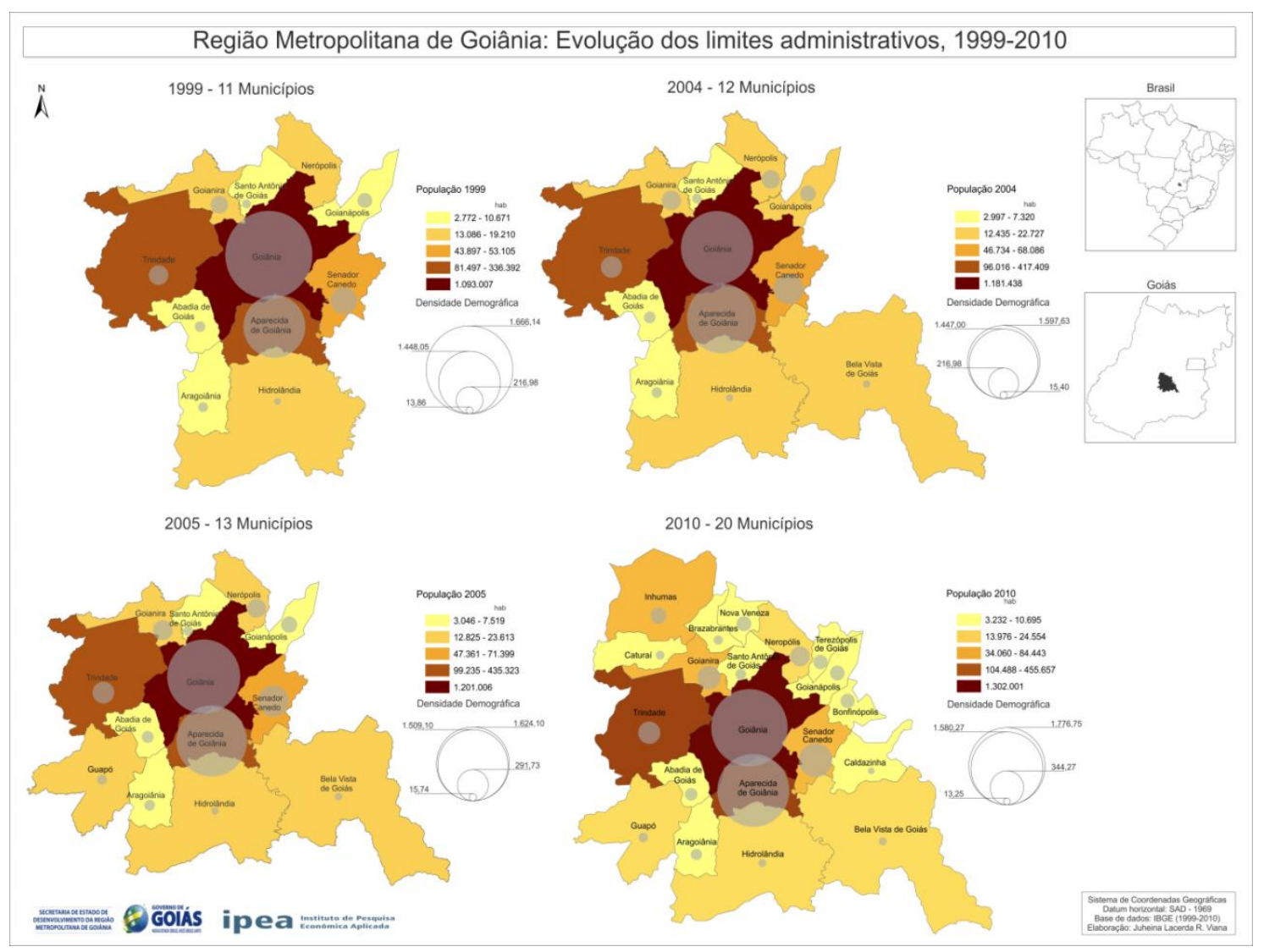

Figura 1. Expansão dos limites administrativos, população e densidade demográfica dos municípios da RMG, 1999-2010. Fonte: IPEA, 2013.

Dos vinte municípios da RMG, apenas quatro - Goiânia, Aparecida de Goiânia, Senador Canedo e Trindade - concentravam em 2010 (IBGE), cerca de 90\% da população metropolitana, esses municípios apresentam as densidades demográficas mais altas da região. No total da população estadual, a participação da população metropolitana evoluiu de 34,8\% para 36,2\%, entre 2000-2010, enquanto a população urbana passou de $38,6 \%$ para $39,3 \%$ no mesmo período, o que lhe confere um elevado grau de urbanização de $98 \%$.

${ }^{2}$ Criada pela Lei Complementar nº. 27, dez/1999, Goiás. 
Os efeitos do acelerado processo de urbanização é um dos principais impactos produzidos no ciclo hidrológico e na qualidade das águas, Tucci (2000) considera que os problemas decorrentes da urbanização, como o aumento da densidade populacional, de construções e da cobertura asfáltica, e suas consequências, incidem sobre a quantidade e qualidade das águas.

Os dados demográficos evidenciam o processo de acelerado crescimento populacional da RMG nos últimos anos, a Figura 2 mostra duas das causas fundamentais dos impactos nos ecossistemas aquáticos continentais de superfície e subterrâneos: o crescimento da população urbana e a evolução do grau de urbanização na RMG.

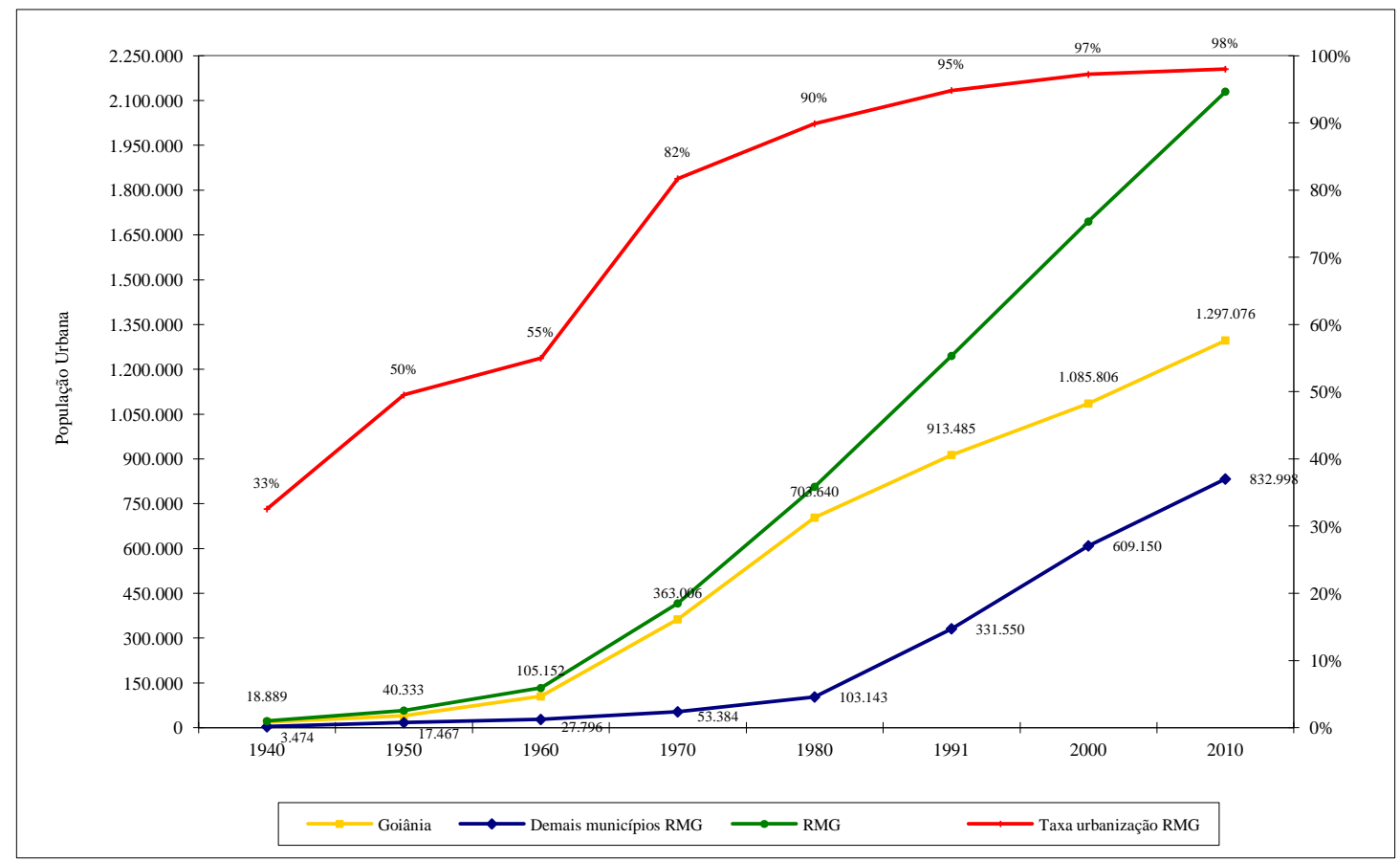

Figura 2. Tendências atuais do crescimento da população urbana na RMG Fonte: IBGE (Censos Demográficos). Elaboração própria.

O crescimento da população e os padrões gerais de consumo humano afetam praticamente todas as atividades econômicas que dependem de serviços dos ecossistemas aquáticos. As diversificadas atividades humanas e o acúmulo de usos múltiplos produzem diferentes ameaças e problemas para a disponibilidade de água e causam riscos elevados. 
Ao debater sobre as questões ambientais e sociais no urbano, Sposito (2005) destaca que o processo de urbanização no mundo contemporâneo, tem provocado o aprofundamento das contradições entre o ambiental e o social nos espaços urbanos. Assim, problemas urbanos, como assoreamento de cursos d’água, poluição da água, uso de áreas para deposição de lixo, entre outros, são na essência, problemas decorrentes do descompasso entre o tempo da natureza e o tempo da sociedade.

A capital-administrativa de Goiás, Goiânia, muito contribuiu para o acelerado processo de urbanização do estado e região, classificada como metrópole regional pelo IBGE, destaca-se como a principal centralidade da região e do estado, possui aproximadamente 1,3 milhões de habitantes (IBGE, 2010), que representavam 23,9\% da população urbana do estado. A cidade apresenta-se densamente urbanizada (Figura 3), sendo a quase totalidade dos bairros ocupada por edificações e ruas pavimentadas, à exceção da superfície formada pelos cursos de água e de áreas verdes representadas por alguns parques, praças, bosques.

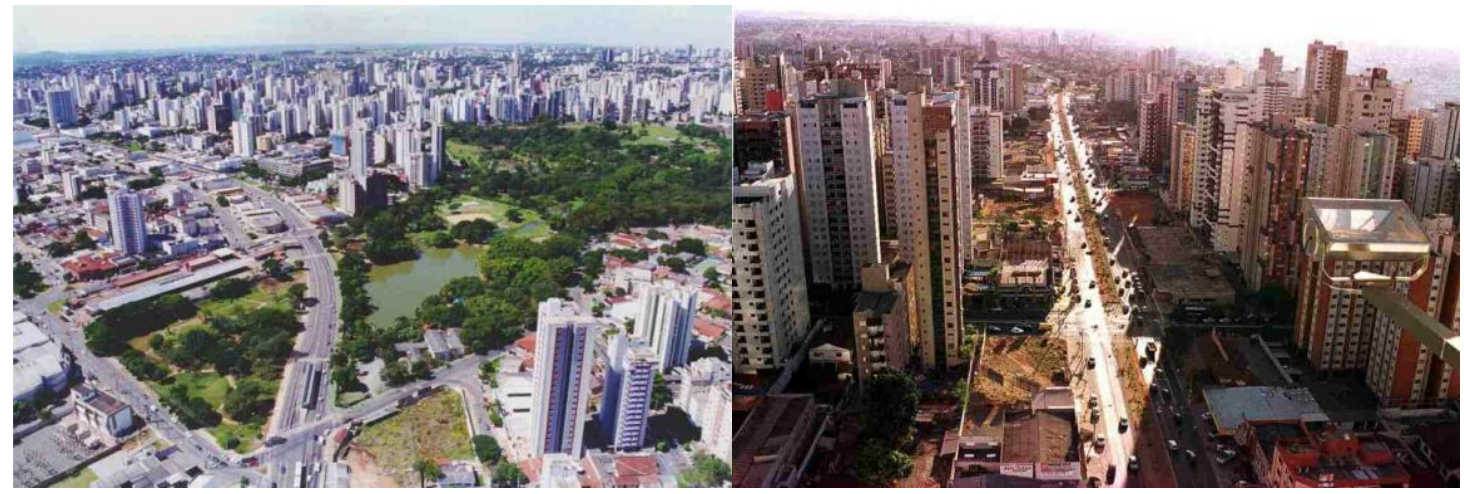

Figura 3. Vista de Goiânia - densidade construtiva Fonte: Google - imagens de Goiânia, acessado em julho/2014.

A partir de 1950, Goiânia atraiu migrantes de muitos lugares, foram três décadas de intenso crescimento populacional expressas em taxas de crescimento geométrico anual, com média entre 10\% e 12,8\% (IBGE), o gráfico da Figura 2 demonstra o rápido crescimento da população urbana de Goiânia, decorrente do elevado êxodo rural, do avanço da fronteira agropecuária e do uso agrícola.

Goiânia desde sua construção funcionou como um grande atrativo de população, proporcionando a toda região central do estado grandes mudanças, desenvolvendo não apenas o seu território municipal, como 
também muitas cidades do seu entorno, tornando essa região uma das mais adensadas do estado (DEUS, 2002).

No período de 1930 a 1960 ocorreram modificações relevantes e estruturais em Goiás, tais como, a edificação de Goiânia e a abertura da rodovia Belém-Brasília rearticulando os centros urbanos regionais e facilitando a integração nacional, que foi efetivada com a construção da capital federal Brasília. Após 1970, a industrialização da agricultura transformou a estrutura socioeconômica regional. A modernização em Goiás concentrava-se nas regiões centro e sul do estado. Durante esse período ocorreu um notável êxodo rural e acelerado incremento nas áreas urbanas, palco de acelerada urbanização (ESTEVAM, 2004).

Arrais (2013) fez uma leitura do conteúdo regional da urbanização de Goiás, entre as décadas de 1960 e 1980, considerando como o período inicial da urbanização do território goiano, acionado pela migração campo-cidade estadual e interestadual, e reconhecendo a hegemonia de Goiânia na oferta de trabalho, bens e serviços, ou seja, de oportunidades para os migrantes.

Com o crescimento das últimas décadas, Goiânia propagou-se em direção às cidades vizinhas, formando uma região metropolitana que atualmente envolve dezenove cidades, das quais quatro delas - Aparecida de Goiânia, Senador Canedo, Goianira, Trindade - encontram-se em avançado processo de conurbação com Goiânia.

Os municípios da RMG apresentam elevada população urbana, com diferentes níveis de integração na dinâmica metropolitana ${ }^{3}$, localizam-se em áreas contíguas à Goiânia, demonstram relações socioeconômicas intensas, decorrentes de especialização, complementação e/ou suplementação funcional e dispõem de relativa mobilidade; dezoito municípios da RMG estão integrados à Rede

\footnotetext{
3 A classificação do nível de integração dos municípios metropolitanos foi elaborada no âmbito do estudo Como Anda Goiânia, MOYSÉS (Org., 2009), coleção Como Anda as Metrópoles Brasileiras. In: LIMA, J. J. F. e MOYSÉS, A. (Org.), Como Andam Belém e Goiânia. Série Como Andam as Regiões Metropolitanas - Letra Capital/Observatório das Metrópoles. 2ª Ed. V. 11. P. 85-121. Rio de Janeiro, 2009.
} 
Metropolitana de Transportes Coletivos, favorecendo o acesso aos equipamentos e serviços e ao mercado de trabalho da metrópole.

\section{Caracterização, Ameaças e Riscos ao Sistema Produtor de Água da RMG}

A maioria dos municípios de Goiás é abastecida por sistemas isolados, que atendem a $97 \%$ das sedes urbanas. Contudo, os sistemas integrados são responsáveis pelo abastecimento de $30 \%$ da população, devido, principalmente, à parcela da RMG atendida pelos sistemas integrados Meia Ponte e João Leite, que possuem capacidade instalada de $4,4 \mathrm{~m}^{3} / \mathrm{s}$ e abastecem de forma integrada Goiânia, Trindade e Aparecida de Goiânia. (ANA, 2010).

Localizada na região central de Goiás, a RMG é banhada pela bacia hidrográfica do Rio Meia Ponte (que perpassa 16 municípios metropolitanos, num total de 39 municípios goianos), e seus dois principais afluentes; rio Caldazinha e Ribeirão João Leite, os quais cortam a região norte da capital goiana, e de onde provém a maior barragem de abastecimento de água que beneficia a RMG.

A bacia do Rio Meia Ponte vem sofrendo forte processo de degradação em vista da urbanização acelerada no decorrer dos anos, com a contaminação das águas inclusive pela existência de lixões/aterros sanitários dentro das microbacias dos mananciais de abastecimento público ${ }^{4}$.

A bacia hidrográfica do Ribeirão João Leite, localiza-se entre os municípios de Goiânia e Anápolis, abrangendo também os municípios metropolitanos de Goianápolis, Nerópolis e Terezópolis de Goiás.

Ao todo a hidrografia da RMG é composta por 22 sub-bacias hidrográficas; os mananciais de abastecimento de água em utilização dos rios, ribeirões e córregos se encontram dentro do perímetro urbano de Goiânia e a captação de água se faz através dos seus cursos d'água (um total de 85 cursos

\footnotetext{
${ }^{4}$ Casos dos municípios de Guapo e Inhumas, conforme relatório da SANEAGO, de 2012, Localização dos lixões e aterros sanitários nas microbacias dos mananciais de abastecimento público.
} 
d'água) - sendo que todas as sub-bacias pertencem à bacia hidrográfica do Rio Meia Ponte. A Figura 4 mostra a rede hídrica da RMG.

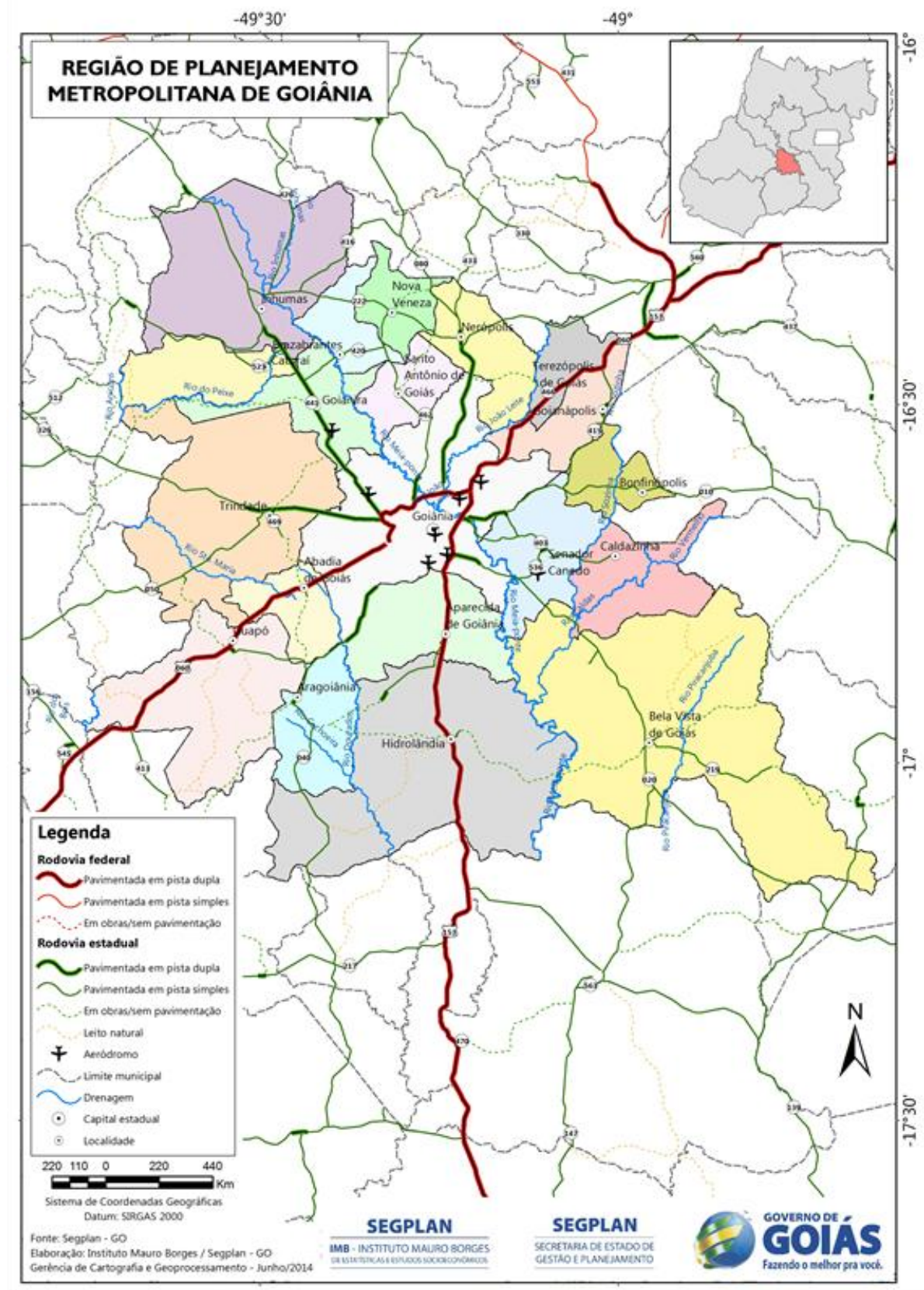

Figura 4. Rede Hídrica Estrutural da Região Metropolitana de Goiânia Fonte: IMB/Segplan, 2014.

A topografia que os cursos d'água estão inseridos na cidade é caracterizada por muitas curvas e as áreas que os margeiam são suscetíveis a inundações, poluição e degradação ocasionada também pela população ribeirinha (UCG, 2003). 
O uso e ocupação do solo nas bacias hidrográficas caracteriza-se pelo forte componente urbano da RMG. A compreensão da sua dinâmica se dá a partir da análise das estruturas urbanas que compõem o espaço metropolitano e da inter-relação entre elas e o ambiente natural.

A expansão urbana desenfreada na região norte de Goiânia atinge as margens do Rio Meia Ponte, comprometendo o principal manancial de Goiás. Um exemplo é o setor Goiânia II às margens do Rio Meia Ponte, que desde sua criação, na década de 1970, foi alvo de criticas por ter sido estruturado em regiões de fundo de vale, contribuindo para o processo erosivo em vertentes, o qual gera assoreamento, poluição e diminuição da vazão do curso d'água. A imagem a seguir (Figura 5) ilustra a ocupação às margens do Rio Meia Ponte, com alta densidade construtiva.

USO E OCUPAÇĂO DAS PROXIMIDADES DO RIO MEIA PONTE - 2010, 2012 E 2013 2013

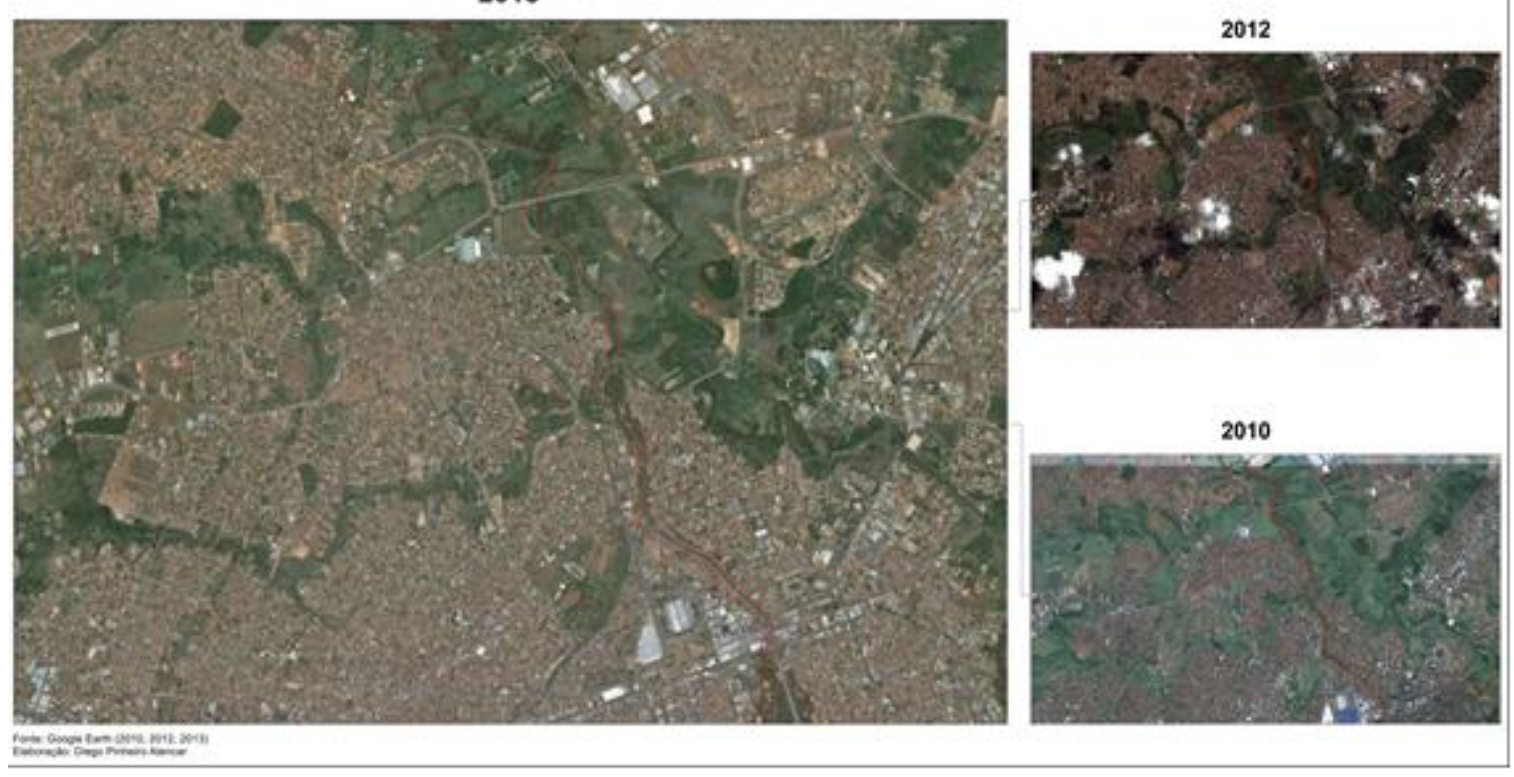

Figura 5. Ocupação do solo nas proximidades do Rio Meia Ponte - 2013 Fonte: Google Earth, 2013. Elaboração: Diego Pinheiro Alencar

A Carta de Risco de Goiânia, publicada em 1991 e reeditada em 2007, condena as construções de alto impacto como as moradias em séries, em áreas de planície próximas ao Rio Meia Ponte e a seus afluentes. No entanto, o setor Goiânia II é hoje uma das localidades com elevada atuação do mercado imobiliário e da expansão urbana de Goiânia. 
Um exemplo de desterritorialização em Goiânia é a Vila Roriz, fundada em 1970, caracterizada por "habitações reduzidas a abrigos temporários e provisórios, para pessoas que vivem numa vila construída sobre um aterro às margens do Rio Meia Ponte e do Ribeirão Anicuns, que são receptores dos esgotos da cidade" (CAM, 2003) e, que, ainda sofre inundações até os dias de hoje.

A RMG ainda possui alguns municípios com características predominantemente rurais, porém os maiores danos ambientais causados ao Rio Meio Ponte provêm das indústrias. Segundo pesquisa de Ribeiro e Leão (2002) estão presentes na RMG os 13 gêneros de indústria de transformação mais poluentes, muitas das quais estão estabelecidas próximas aos cursos d'água do Rio e seus afluentes, e a maioria não possui tratamento próprio de esgoto, fazendo seus despejos diretamente no Rio Meia Ponte ou na rede pública de coleta - os trechos do Meia Ponte que percorrem Goiânia e Inhumas são os mais degradados (62\% de suas Áreas de Proteção Ambiental - APP estão comprometidas). De acordo com a Secretaria Estadual do Meio Ambiente e dos Recursos Hídricos (SEMARH), são lançados no curso do rio, todos os dias, mais de $180 \mathrm{mil} \mathrm{m} 3$ de esgoto e uma tonelada de resíduos sólidos.

O diagnóstico elaborado pela Agência Nacional de Águas, em atendimento à Lei nº 9.433 de 1997 identificou regiões estratégicas para a gestão dos recursos hídricos em função do uso intensivo da água e do comprometimento da sua qualidade na bacia do Rio Paranaíba; da qual a bacia do Rio Meia Ponte é integrante, segundo o qual de todos os mananciais que integram essa bacia hidrográfica, a situação do Rio Meia Ponte é a mais preocupante. As maiores concentrações de trechos em condições ruins relativas aos parâmetros de coliformes fecais, oxigênio e fósforo - que indicam a qualidade da água - principalmente na RMG. O trecho do rio que passa por Goiânia foi enquadrado pela ANA na classe 4 de uma escala na qual 0 é excelente e 4 é péssimo, razão pela qual o Rio Meia Ponte ocupa 0 posto de sétimo rio mais poluído do Brasil

\footnotetext{
${ }^{5}$ As margens da Vila Roriz. Documentário -Vídeo Ambiental vencedor do Prêmio Fio Cruz, 2007.
} 
A contaminação das águas subterrâneas é uma fonte importante de deterioração dos recursos hídricos e das reservas disponíveis. Tundisi (2009) discute os principais problemas e processos relacionados com a contaminação de águas superficiais, os resultados de seus estudos mostram que os problemas de deterioração estão relacionados com o crescimento e a diversificação das atividades agrícolas, o aumento da urbanização e o aumento e a intensificação das atividades nas bacias hidrográficas. Outro problema é a falta de tratamento de esgotos e a contaminação nas grandes cidades e metrópoles, principalmente em países em desenvolvimento.

Com o crescimento desordenado, e sem regras para uso e ocupação do solo, a barragem do João Leite também sofre degradação devido à ação antrópica e a especulação imobiliária. Todos os cursos d'água que cortam a malha urbana de Goiânia estão parcialmente ou totalmente comprometidos, no que se refere à qualidade ambiental. As margens foram ocupadas ilegalmente e desmatadas até o limite do canal. A imagem (Figura 6) a seguir ilustra a ocupação às margens do João Leite.

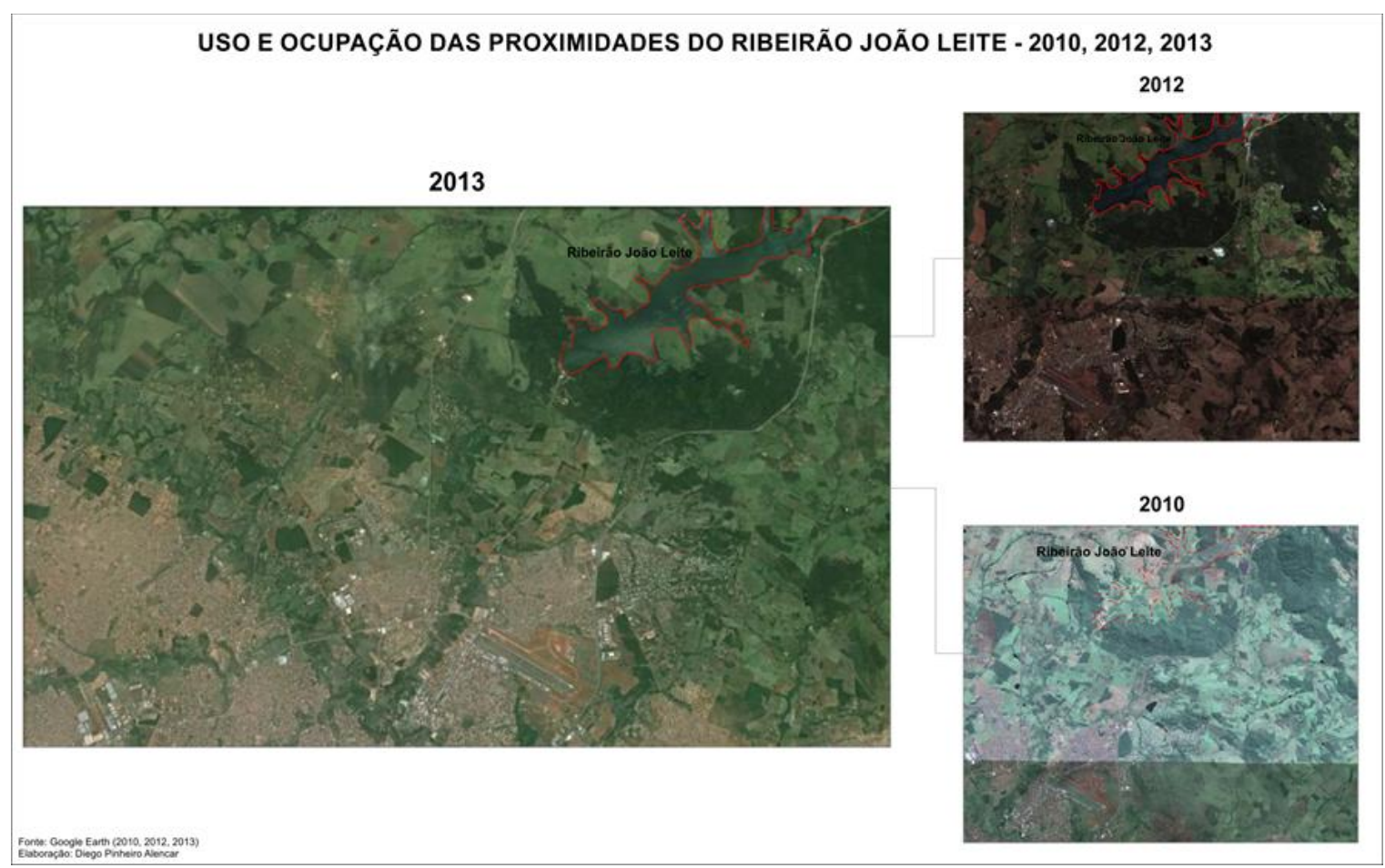

Figura 6. Ocupação do solo nas proximidades da Represa do João Leite - 2013 Fonte: Google Earth, 2013. Elaboração de Diego Pinheiro Alencar 
Apesar de todos os alertas contra a ocupação das proximidades da barragem do Ribeirão João Leite, 0 que representa risco concreto à qualidade da água que abastecerá a RMG pelas próximas décadas, investidores do setor imobiliário insistem na exploração da área.

A barragem foi fechada no dia 11 de dezembro de 2009, iniciando o represamento do João Leite. Contudo, no dia 14 de julho de 2010, o prefeito municipal de Goiânia assinou quatro decretos autorizando a criação de quatro loteamentos na região abaixo do reservatório: Flores do Parque, Frei Galvão (MCMV), Portal da Mata e Bela Goiânia. Um deles fica distante menos de 500 metros da barragem e, consequentemente, do Lago, mas fora da área protegida. A área ocupada pelos loteamentos é de 220,7 hectares e eles vão criar pelo menos 1.350 lotes. Os loteamentos estão posicionados entre o Residencial Vale dos Sonhos e a barragem do João Leite.

Nas adjacências do município de Terezópolis de Goiás, a implantação dos loteamentos Flora Terezópolis e Jardim Potala (600 unidades), em 2013, próximos ao reservatório do João Leite, também ameaçam a qualidade da água. Conforme o ministério Público de Goiás, irregularidades impossibilitariam construções no local, além da possibilidade de contaminação da barragem, já que a área fica próxima ao ponto de captação de água, razão pela qual o MP entrou com ação para impedir a comercialização de lotes dos empreendimentos. No entanto, a SEMARH já havia concedido o licenciamento ao empreendimento e a Câmara Municipal já tinha aprovado o loteamento, que precisaria ser revogado.

Visando brecar a expansão imobiliária ao redor do Lago, em 2011, a SEMARH anunciou a criação do Parque Estadual do João Leite, com a ideia de criar um cinturão verde de proteção ao redor do reservatório. Mas iniciativas nesse sentido e para a gestão da Água na RMG ainda são tímidas.

\section{Limites e Estratégias para Gestão da Água na RMG}

No início do século XXI, entre outras crises séries, a crise da água é uma ameaça permanente à humanidade e à sobrevivência da biosfera como um todo. Esta crise tem grande importância e interesse 
geral: além de colocar em perigo a sobrevivência do componente biológico, ela impõe dificuldades ao desenvolvimento, produz estresses econômicos e sociais, e aumenta as desigualdades entre regiões e países. A água sempre foi um recurso estratégico à sociedade. 0 crescimento populacional e as demandas sobre os recursos hídricos superficiais e subterrâneos são algumas das causas fundamentais da crise (TUNDISI, 2009).

Os limites definidos pela disponibilidade hídrica na RMG foram avaliados na pesquisa de Pasqualetto et. all (2004) comparando-se diferentes projeções de demanda, com cenários para os próximos 50 anos. Segundo os autores, nas condições do cenário atual de taxa geométrica de crescimento de $2,2 \%$ e considerando a inexistência de programas efetivos de conservação dos mananciais, as potencialidades de recursos hídricos seriam esgotadas entre os anos de 2025 e 2030. Para estes autores, a implantação da APA João Leite e as ações dirigidas à bacia hidrográfica são de fundamental importância para a concretização efetiva de preservação deste manancial hídrico e a segurança de qualidade de água oferecida a população, bem como a garantia futura de sua disponibilidade.

A Saneamento de Goiás S.A. - SANEAGO é a empresa responsável pelo saneamento na RMG, uma sociedade de economia mista, que detém o monopólio do serviço público na quase totalidade dos municípios metropolitanos: a única exceção é o município de Senador Canedo, cuja gestão é atribuição da Prefeitura.

Para a garantia do abastecimento da RMG até o horizonte de planejamento, destaca-se a entrada em operação da barragem do João Leite (Figura 7), com 129 milhões de $\mathrm{m}^{3}$, que visa regularizar a vazão do manancial já em utilização, e a implementação de adequações ao sistema produtor - novas adutoras e ETA (em construção) elevando sua capacidade nominal de 2,0 para $4,0 \mathrm{~m}^{3} / \mathrm{s}$. 


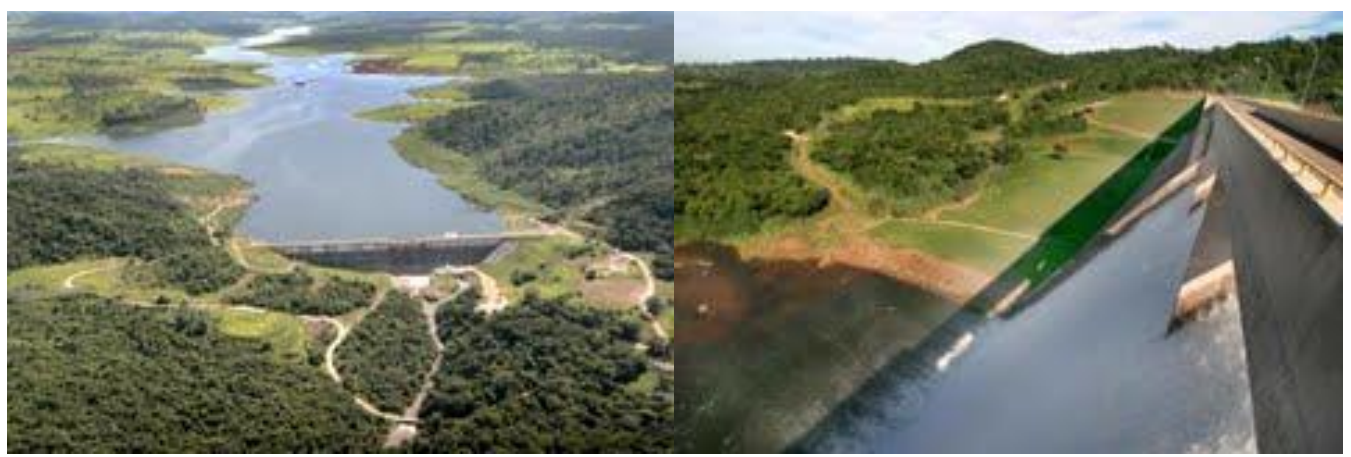

Figura 7. Barragem Ribeirão João Leite

Fonte: SANEAGO, Notícias/Goiás Agora. Disponível em: http://www.noticias.go.gov.br/. Acesso: set/2013

O conjunto de obras do Sistema Produtor denominado Mauro Borges (Figura 8) engloba um complexo de instalações (barragem, tubulações, reservatório/adutoras, estação de tratamento, elevatórias e redes de distribuição) que foram divididos em dois módulos: contemplados com recursos do Programa de Aceleração de Crescimento - PAC 1 e 2, envolvendo investimentos que somam cerca de R\$1 bilhão, com previsão para início de operação no segundo semestre de 2014.
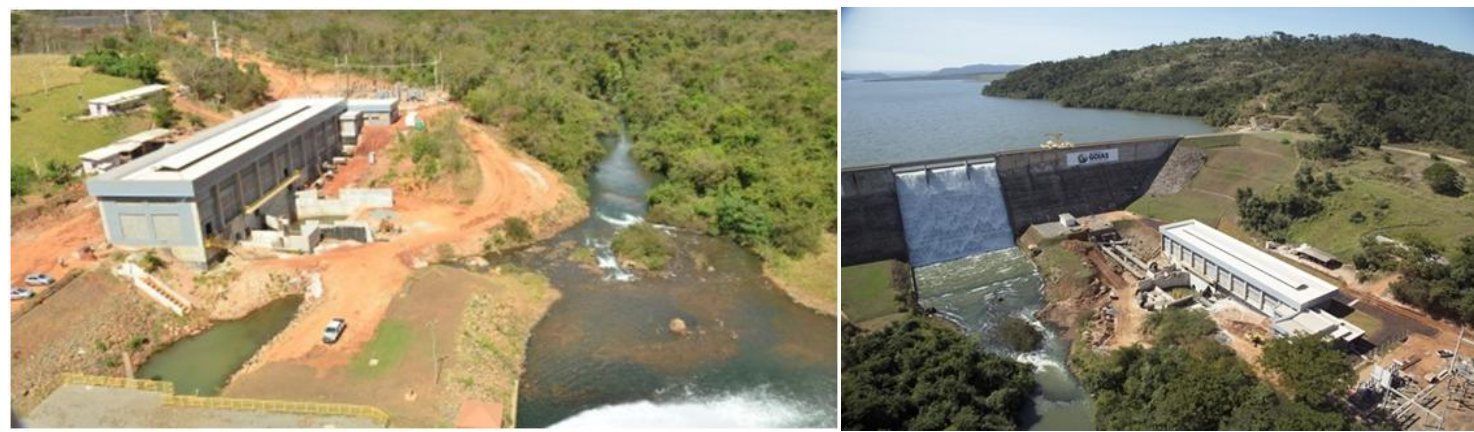

Figura 7. Obras do Sistema Produtor Mauro Borges.

Fonte: SANEAGO, Notícias/Goiás Agora. Disponível em: http://www.noticias.go.gov.br/. Acesso: set/2013.

A SANEGO anunciou em junho de 2014 o início da fase de conclusão da obra, que dobrará a capacidade de produção de água tratada, garantindo o abastecimento para os moradores da RMG até o ano de 2040. Segundo a empresa, depois de pronta, a ETA poderá tratar até 21,6 milhões de litros de água por hora e terá dois reservatórios com capacidade para armazenar 40 milhões de litros de água tratada.

Embora a função pública de saneamento ambiental na RMG não possa ser caracterizada como uma política metropolitana propriamente dita, formulada e gerida para o atendimento integrado dos 
municípios metropolitanos, o sistema Mauro Borges é a estratégia definida pela SANEAGO para garantir o abastecimento de água, de forma barata e abundante, para todas as cidades que compõem a RMG, assegurando por pelo menos 30 anos um eficiente fornecimento, mesmo nos períodos de seca prolongada ${ }^{6}$

A julgar pelas expectativas, parecem ignorar, portanto, a questão da degradação ambiental, a necessidade de proteção dos recursos hídricos da bacia hidrográfica e das matas ciliares, os impactos do crescimento demográfico, das ocupações irregulares nas proximidades dos mananciais, do despejo clandestino de esgoto e entulhos, entre outros.

Na questão de recuperação de áreas degradadas dos mananciais hídricos, na maioria das vezes degradadas pelo lançamento de lixo, pela ocupação irregular de famílias invasoras e pelo desmatamento da vegetação que fica às margens do manancial. A Agência Municipal de Meio Ambiente (AMMA) de Goiânia implantou um projeto de Revitalização de Nascentes, através do Programa de Parceria para Recuperação dos Mananciais de Goiânia, onde empresários podem somar seus esforços aos da Prefeitura e participar de projetos para preservar os rios, córregos, lagos e nascentes que existem na capital, as ações incluem: transferência de famílias invasoras; roçagem; retirada de entulho; replantio de árvores e recomposição florística, tendo como parceiros, principalmente, escolas de ensino médio.

No âmbito da gestão dos resíduos sólidos na RMG faz-se importante destacar iniciativa de articulação intermunicipal em gestação: trata-se do Consórcio Público de Manejo de Resíduos Sólidos e das Águas Pluviais da Grande Goiânia, constituído através de protocolo de intenções do consórcio da região AMAMPA - Associação dos Municípios do Alto Meia Ponte da Grande Goiânia e municípios adjacentes.

\footnotetext{
${ }^{6}$ SANEAGO. Obras do sistema João Leite entram na reta final. Goias Agora, 13 de setembro de 2013. In: http://www.goiasagora.go.gov.br/obras-do-sistema-joao-leite-entram-na-reta-final/
} 
Porém, não existe um Plano Setorial de Saneamento Ambiental na RMG ou uma carteira de projetos e/ou investimentos vinculados a um Plano Metropolitano. Em geral, os projetos e recursos são direcionados para situações mais críticas, como os casos de: Aparecida de Goiânia, que tem intervenção do Ministério Público na questão da água (cobertura de apenas $60 \%$ e qualidade nociva à saúde humana), contando com recursos da própria SANEAGO, do BID, do PAC e do FGTS, e de Senador Canedo, contemplado no PAC 1 para a construção do sistema de esgoto sanitário na cidade - até então inexistente.

Em toda a RMG, no período entre 2008-2012, os empreendimentos relativos à Saneamento, Água em Áreas Urbanas, Recursos Hídricos e ampliação da cobertura da rede de esgoto, se aproximaram a RS 1 bilhão de reais em investimentos, com recursos próprios da SANEAGO, do Orçamento Geral do Estado (OGE), do BID, do PAC (Etapas 1 e 2) e do FGTS.

Além de ter ampliada a capacidade de abastecimento, os sistemas estão recebendo obras de ampliação e melhorias que possibilitarão o aumento de produção, reserva e distribuição de água. Existem importantes projetos em andamento nos municípios da RMG. A meta da SANEAGO é sanar definitivamente a crise de desabastecimento enfrentada por bairros da capital Goiânia e da cidade vizinha Aparecida de Goiânia durante o período de estiagem ${ }^{7}$. Com o funcionamento de novos e modernos equipamentos automatizados, pretende-se proporcionar regularidade no serviço e ampliar a vazão atual de 650 para 1.000 litros por segundo.

\section{CONSIDERAÇÕES FINAIS}

Em geral, as grandes cidades e as regiões metropolitanas, em decorrência do crescimento populacional, do alto grau de urbanização e dos usos múltiplos, que afetam a quantidade e a qualidade de água, são exemplos evidentes de problemas de proteção de mananciais, de tratamento e de distribuição de águas. Com mais de 2 milhões de habitantes na Região Metropolitana de Goiânia, a região concentra população e a maior parte das atividades culturais, econômicas e industriais de Goiás, com forte

\footnotetext{
${ }^{7}$ Só na primeira quinzena do mês de julho de 2013 já sofrem de interrupção do serviço de água cerca de 20 bairros do município de
} Aparecida de Goiânia, com notificação pela SANEAGO. 
polarização na cidade de Goiânia, que apresenta grande peso no processo de urbanização do estado. A situação de abastecimento de água da capital e região está próxima a uma crise de "falta de água".

A recente e rápida expansão da $\mathrm{RMG}$, com o crescimento populacional, econômico e social, tem produzido pressões sobre o ciclo hidrológico e sobre as reservas de águas superficiais e subterrâneas da região, agregando dificuldades para atender e oferecer água tratada com qualidade e suficiência às necessidades da população urbana e das atividades a elas relacionadas sejam pessoais, domésticas, industriais, municipais, etc. A ameaça em relação às dificuldades de abastecimento futuro de água na RMG, em vista de atender uma demanda crescente, com intensificação e especialização dos usos múltiplos de águas, requer um sistema produtor de abastecimento que tenha capacidade para o atendimento da demanda diversificada.

Do total das sedes urbanas do estado, $62 \%$ têm o seu abastecimento associado a mananciais superficiais. A dependência dessas fontes hídricas é mais frequente nos municípios de maior porte e os situados na RMG, onde o sistema de abastecimento de água provém quase que exclusivamente, do terço superior da bacia hidrográfica do Rio Meia Ponte e da metade inferior da sub-bacia do Ribeirão João Leite que cortam a região. 0 crescimento urbano desordenado ocupando áreas próximas aos mananciais está aumentando muito a necessidade de investimentos para ampliar a rede de distribuição de água potável.

Dentre as soluções propostas para enfrentar a crise anunciada de "falta de água" na RMG, destacamse a barragem João Leite, a implementação de adequações ao sistema produtor - novas adutoras e ETA (em fase de conclusão).

Contudo, a proteção dos principais mananciais que abastecem Goiânia é vital para a garantia hídrica futura. No Rio Meia Ponte, por exemplo, é necessário evitar o comprometimento da qualidade das águas por poluição urbana. O Ribeirão João Leite, em função da construção da barragem, também requer cuidados especiais relacionados ao controle das fontes poluidoras e ações de gestão para a compatibilização dos usos múltiplos no reservatório. 


\section{REFERÊNCIAS}

ANA, Agência Nacional de Águas. Atlas Brasil: abastecimento urbano de água: resultados por estado. Brasília: ANA: Engecorps/Cobrape, 2010.

ARRAIS, Tadeu A. A produção do território goiano: economia, urbanização, metropolização. Goiânia: Ed. UFG, 2013.

CAM, Luis. As Margens da Vila Roriz. Direção: Luis Cam. Cidade de Goiás, V Festival Internacional de Cinema Ambiental FICA, 2003. Documentário sobre o significado de habitações reduzidas a abrigos provisórios, construídos em aterros, às margens de um córrego repleto de esgotos. Disponível: http://fica.art.br/v-fica-filmes-selecionados/. Acesso: ago/2013.

DEUS, João B. de. O Sudeste Goiano e a desconcentração industrial. Brasília: Ministério da Integração Nacional: Universidade Federal de Goiás, 2002.

ESTEVAM, Luís. O tempo da transformação: estrutura e dinâmica da formação econômica de Goiás. $2^{\text {a }}$ ed. Goiânia: Editora da UCG, 2004.

IBGE, Instituto Brasileiro de Geografia e Estatística. Censos Demográficos. Rio de Janeiro: IBGE.

IMB, Instituto Mauro Borges de Estatística e Estudos Socioeconômicos. Regiões de Planejamento de Goiás, 2013.

IPEA, Instituto de Pesquisa Econômica Aplicada. Relatório 1.1. Região Metropolitana de Goiânia. Projeto: Governança Metropolitana no Brasil, Marco Aurélio Costa (coord.), 2013.

PASqUALETTO, Antônio; ALCÂNTARA, Christiane R. de; RAMOS, Frederico P.; PATRÍCIO, Gleides M. R. e SILVA, Hildefonsina M. Escassez de água como limitador do desenvolvimento da Região Metropolitana de Goiânia. (mimeo). PUC/GO - curso de Engenharia Ambiental, Goiânia, 2004.

RIBEIRO, Francis L. e LEÃO, Carlos. Valor econômico dos danos ambientais do rio Meia Ponte em Goiânia. Revista Sociedade e Cultura: pesquisas e debates em Ciências Sociais/UFG. V. 4, nº 1, 2001.

SPOSITO, Maria E. B. Os embates entre as questões ambientais e sociais no urbano. In: CARLOS, Ana F. A.; LEMOS, Amália I. G. (orgs.). Dilemas urbanos: novas abordagens sobre a cidade. 2 ed. São Paulo: Contexto, 2005, p. 295 -298.

TUCCI, Carlos E. M. Hidrologia: ciência e aplicação. 2 ed. Ed. UFRGS, ABRH, 2000.

TUNDISI, José G. Água no Século XXI: Enfretamento e Escassez. 3 ed. São Carlos: RiMa, IIE, 2009.

UCG, Universidade Católica de Goiás. Agenda 21 Goiânia. ARCA, 2003.

\section{BIBLIOGRAFIA COMPLEMENTAR}

BRASIL, Governo Federal. PAC - Programa de Aceleração do Crescimento - 6º Balanço do PAC 2 - GOIÁS - 2012-2014. Brasília - DF, 2013. 
CUNHA, Débora F. da e BORGES, Elcileni M. Urbanização acelerada e o risco de desabastecimento de água na Região Metropolitana de Goiânia: o desafio do sistema produtor João Leite. In: Anais do VI Congresso Iberoamericano de Estudios Territoriales y Ambientales. São Paulo, set./2014, p. 1126-44.

GOUVÊIA, R.G. A Questão Metropolitana no Brasil. Ed. FGV, Rio de Janeiro, 2005.

MANOEL, L. C. Gestão das Águas. Disponível em: http://www.meiaponte.org - Acesso em setembro de 2003.

MOYSÉS, A. Goiânia, metrópole não planejada. Goiânia: Editora da UCG, 2004.

MOYSÉS, Ary; CUNHA, Débora F. da e BORGES, Elcileni M. O estado de Goiás e a Região Metropolitana de Goiânia no Censo 2010. Boletim Informativo do Observatório das Metrópoles/INCT-CNPq. Ano III, nº 196, p. 1-27, 03 de agosto de 2011. In: www.observatoriodasmetropoles.net

PLANO DIRETOR DE GOIÂNIA. Lei Complementar $n^{\circ}$. 171. Diário Oficial n ${ }^{\circ} 4.147$ de 26 de junho de 2007.

SANEAGO, Saneamento de Goiás S. A. Planos Diretores de Água e Esgoto de Goiânia e Áreas Conurbadas. Consorcio Tecnosan - Prodec, 2003.

Levantamento da Localização dos Lixões, Aterros Controlados e/ou Sanitários nas Bacias dos Mananciais de Abastecimento Público. Goiânia, 2010.

Localização dos de lixões e aterros sanitários nas microbacias dos mananciais de abastecimento público Relatório. Goiânia, 2012.

SEMARH - Secretaria do Meio Ambiente e dos Recursos Hídricos. Diagnóstico do monitoramento dos sistemas de disposição do lixo urbano dos municípios goianos. Goiânia, 2009.

Diagnóstico do Monitoramento dos Sistemas de Disposição do Lixo Urbano dos Municípios Goianos Relatório. Goiânia, 2009.

UFG, Universidade Federal de Goiás. METRÓPOLE - A história do crescimento de Goiânia reside hoje no enfrentamento de questões relacionadas à consolidação de uma metrópole. Revista Afirmativa, Goiânia, jan./2013. 